\title{
A qualitative study of factors influencing male participation in fertility research
}

\author{
Alyssa F. Harlow ${ }^{1 *} \mathbb{D}$, Amy Zheng ${ }^{1}$, John Nordberg ${ }^{1}$, Elizabeth E. Hatch', Sam Ransbotham² and Lauren A. Wise
}

\begin{abstract}
Background: Although fertility is a couple-based outcome, fertility studies typically include far fewer males than females. We know little about which factors facilitate or inhibit male participation in fertility research. In this study we aimed to explore factors that influence male participation in fertility research among North American couples trying to conceive.

Methods: We conducted a qualitative research study of male participation in Pregnancy Study Online (PRESTO), a prospective preconception cohort of couples actively trying to conceive in Canada and the United States. Between January-August 2019, we carried out 14 online one-on-one in-depth interviews and one online focus group of males and females with varying levels of participation. The in-depth interviews included females who enrolled in PRESTO but declined to invite their male partners to participate $(n=4)$, males who enrolled in PRESTO $(n=6)$, and males who declined to participate in PRESTO $(n=4)$. The focus group included 10 males who enrolled in PRESTO. We analyzed the transcriptions using inductive content analysis.
\end{abstract}

Results: Male and female participants perceived that fertility is a women's health issue and is a difficult topic for men to discuss. Men expressed fears of infertility tied to masculinity. However, men were motivated to participate in fertility research to support their partners, provide data that could help others, and to learn more about their own reproductive health.

Conclusions: Male participation in fertility studies will improve our understanding of male factors contributing to fertility and reproductive health issues. Results indicate a need for more education and health communication on male fertility to normalize male participation in fertility and reproductive health research.

Plain English Summary: Men are much less likely than women to participate in research on fertility and pregnancy. However, it is important for men to participate in fertility research so that we gain a better understanding of male factors that impact fertility and pregnancy outcomes. In this qualitative study, we interviewed men and women from Canada and the United States who were trying to become pregnant to understand why men choose to participate in fertility research, why men choose not to participate in fertility research, and why women choose not to invite their male partners to participate in fertility research. We found that both men and women believe fertility is a woman's health issue. Men find it difficult to talk about pregnancy and fertility and have fears of infertility tied to masculinity. However, men are motivated to participate in fertility research to support their partners, to help others, and to learn more about their own reproductive health.

\footnotetext{
*Correspondence: afharlow@bu.edu

${ }^{1}$ Department of Epidemiology, Boston University School of Public Health,

715 Albany Street, Boston, MA 02188, USA
}

Full list of author information is available at the end of the article original author(s) and the source, provide a link to the Creative Commons licence, and indicate if changes were made. The images or other third party material in this article are included in the article's Creative Commons licence, unless indicated otherwise in a credit line to the material. If material is not included in the article's Creative Commons licence and your intended use is not permitted by statutory regulation or exceeds the permitted use, you will need to obtain permission directly from the copyright holder. To view a copy of this licence, visit http://creativecommons.org/licenses/by/4.0/. The Creative Commons Public Domain Dedication waiver (http://creativeco mmons.org/publicdomain/zero/1.0/) applies to the data made available in this article, unless otherwise stated in a credit line to the data. 
Keywords: Male fertility, Qualitative research, Male participation, Reproductive health, Research participation, Preconception cohort

\section{Background}

Although fertility is a couple-based outcome and male factors account for $50 \%$ of infertility cases [1], most fertility studies enroll females only and focus only on female determinants. Over the past decade, the National Institutes of Health and other funding bodies have placed greater emphasis on advancing scientific knowledge on male factors that influence fertility [2]. While advanced male age [3, 4], smoking [5-7], obesity [8-10], and other lifestyle factors [11-13] may affect fertility, other male factors are unknown. The lack of knowledge on male factors is partially due to a lack of available data, and the limitations of using female proxies for male exposures [14]. Few males participate in preconception and reproductive studies, and we know little about which factors facilitate or inhibit male participation in fertility research. Understanding these factors can inform targeted recruitment efforts and potentially improve male participation rates in fertility studies.

One barrier to male engagement in reproductive health research is that men may feel disconnected from fertility because women get pregnant, not men [15]. Cultural and gender norms surrounding pregnancy also contribute to men and women perceiving that pregnancy is a woman's domain and that men are not expected to be engaged in the preconception process [15-18]. These cultural norms may also cause investigators not to invite men to participate in studies on reproductive health [19]. Clinical treatment of infertility (e.g., assisted reproduction) tends to focus on female bodies, which in turn contributes to an environment where men feel they are not equal partners in the reproductive process [19-21]. Most research on male engagement in fertility or pregnancy processes includes either couples experiencing infertility, or men from the general population who are not actively trying to conceive with a partner. Few studies examine male participation in fertility research among couples actively trying to conceive.

This study intends to understand the factors contributing to male participation in Pregnancy Study Online (PRESTO), a large preconception cohort study of North American pregnancy planners. Using qualitative research methods, we interviewed men and women from PRESTO to identify factors contributing to participation (or lack thereof) by men in fertility research.

\section{Methods \\ Study design}

We conducted a qualitative substudy among participants of PRESTO, an ongoing web-based prospective cohort study of North American couples attempting to conceive. The study design and methods of PRESTO were described previously [22]. PRESTO aims to identify factors associated with couple fecundability, measured by time to pregnancy. Eligible participants include women 21-45 years old who live in the United States or Canada, live with a male partner, and are actively trying to conceive without fertility treatments. Females complete a baseline questionnaire, after which investigators encourage them to invite their male partners to participate. Men who choose to participate complete a baseline questionnaire and an optional dietary questionnaire. Investigators ask a subset of men who completed the baseline questionnaire to provide a semen sample. About $57 \%$ of female participants invite their male partners to complete the baseline questionnaire, and $50 \%$ of those invited men agree to participate [22].

To understand factors contributing to male participation in PRESTO and fertility research in general, we conducted web-based one-on-one interviews. We interviewed men who were invited but chose not to participate in PRESTO, men who were invited and participated in PRESTO, and women who did not invite their male partners. We then conducted one web-based focus group with a separate sample of male PRESTO participants to confirm emerging results from the one-on-one in-depth interviews [23].

\section{Sampling scheme}

To generate our sample, we used criterion-based purposeful sampling [24]. We selected participants based on characteristics (i.e., criteria) that allowed for detailed exploration of themes relevant to our research questions [24, 25]. Sample criteria included variables associated with male enrollment in a prior quantitative analysis of PRESTO data [22]. We then consulted the principal investigator of PRESTO, a subject-matter expert, to identity additional variables to include in our sampling scheme. We ranked criteria as primary criteria (i.e., variables given first priority in sample structure), secondary criteria (i.e., variables included in sample structure, but considered less important than primary criteria), and tertiary criteria (i.e., variables not specified in sample 
composition, but monitored during recruitment to promote sample diversity) [25].

Our only primary criterion was type of PRESTO respondent: male non-respondents (men who were invited to PRESTO and chose not to participate in any capacity), male respondents (men who were invited to PRESTO and agreed to participate in the baseline and dietary survey, and provided a semen sample), and female non-inviters (women who did not invite their male partners to participate). Our secondary criteria included education ( $<$ college vs. $\geq$ college education), geographical region (four US census regions plus Canada), and pregnancy attempt time at PRESTO baseline $(<3$ vs. $\geq 3$ cycle attempts). Tertiary criteria included female age ( $<30$ vs. $\geq 30$ years), race/ethnicity (Non-Hispanic White, Non-Hispanic Black, Non-Hispanic other race, Hispanic), and relationship length ( $<5 \mathrm{vs.} \geq 5$ years).

For in-depth one-on-one interviews, we aimed to recruit 3-6 participants of each respondent type. Within each respondent type, we purposefully-sampled for diversity of our secondary and tertiary criteria. (Table 1 describes the purposeful sampling matrix) [24]. For our focus group, we aimed to recruit a separate sample of 5-10 men who did not participate in the one-on-one interviews and completed at least the PRESTO baseline questionnaire.

\section{Inclusions and exclusion criteria}

We excluded participants trying to conceive for more than 6 months at enrollment. This is an exclusion criterion for the analysis of fecundability data in PRESTO. We additionally reasoned that women who had been trying to conceive for a longer time might be less likely to invite their male partners. To ensure that participants were able to recall thought processes in choosing whether or not to participate in PRESTO (or in choosing not to invite their partners), participants were eligible for in-depth interviews if they received their invitation to participate in PRESTO (males) or completed the baseline questionnaire (females) within the previous 6 months. Due to a lower response rate, we relaxed this eligibility requirement to invitations within the previous 12 months for focus group participants.

\section{Participant recruitment}

We conducted recruitment and data collection for the in-depth interviews before the focus group. We identified a list of eligible participants that we updated weekly. The Principal Investigator of PRESTO first reviewed the list of eligible participants and identified male respondents she felt would provide information-rich data based on their participation in PRESTO. "Information-rich" data provides in-depth and detailed information on the phenomenon of interest [25]. In the case of our study, we identified male respondents who were particularly engaged in PRESTO, as demonstrated by their e-mail correspondence and timeliness of survey completion. We contacted these information-rich participants first, followed by randomly selected participants from the remaining list of eligible participants. We e-mailed selected participants details of the qualitative study, including the research aims, types of questions, anticipated length of the interview, interview format, and compensation. We repeated this process for focus group participants after completion of in-depth interviews, with the focus group date established a priori. Participants received a reminder e-mail one week and 24-h before the scheduled interview or focus group.

\section{Study sample}

We invited 26 male respondents, 51 male non-respondents, and 21 females to participate in the in-depth interviews (contacted no more than twice). The final sample for in-depth interviews included 6 male respondents

Table 1 Sampling Matrix for in-depth interviews

\begin{tabular}{|c|c|c|c|c|}
\hline \multirow[t]{2}{*}{ Secondary sample criteria } & \multicolumn{4}{|l|}{ Primary sample criteria } \\
\hline & Male respondent & Male non-respondent & Female non-inviters & Total \\
\hline Education & $\begin{array}{l}\geq 1 \text { with less than college } \\
\text { education and } \geq 1 \text { with col- } \\
\text { lege education }\end{array}$ & $\begin{array}{l}\geq 1 \text { with less than college } \\
\text { education and } \geq 1 \text { with col- } \\
\text { lege education }\end{array}$ & $\begin{array}{l}\geq 1 \text { with less than college } \\
\text { education and } \geq 1 \text { with col- } \\
\text { lege education }\end{array}$ & \\
\hline US census regions and Canada & $\begin{array}{l}\geq 2 \text { different regions repre- } \\
\text { sented }\end{array}$ & $\begin{array}{l}\geq 2 \text { different regions repre- } \\
\text { sented }\end{array}$ & $\begin{array}{l}\geq 2 \text { different regions repre- } \\
\text { sented }\end{array}$ & $\begin{array}{l}\text { At least all five rep- } \\
\text { resented across } \\
\text { total sample }\end{array}$ \\
\hline $\begin{array}{l}\text { Pregnancy attempt time at } \\
\text { enrollment in PRESTO }\end{array}$ & $\begin{array}{l}\geq 1 \text { with }<3 \text { cycles and } \geq 1 \\
\text { with } 3-6 \text { cycles }\end{array}$ & $\begin{array}{l}1 \text { with }<3 \text { cycles and } \geq 1 \text { with } \\
3-6 \text { cycles }\end{array}$ & $\begin{array}{l}1 \text { with }<3 \text { cycles and } \geq 1 \text { with } \\
3-6 \text { cycles }\end{array}$ & \\
\hline Targeted n & $3-6$ & $3-6$ & $3-6$ & $9-18$ \\
\hline
\end{tabular}

Across total sample, monitor for diversity in race/ethnicity, female partner age and relationship duration

Sample matrix developed using steps outlined in Ritchie, Lewis \& Elam (2013) 
(response percentage: 23\%), 4 male non-respondents $(8 \%)$, and 4 female non-inviters (19\%). We contacted 170 men for the focus group. The final focus group sample included 10 male participants (6\%).

\section{Data collection}

We held the interviews and the focus group between January-August 2019 using Zoom Video Communications (C) (Zoom) web-conference video technology (version 4.1), consistent with PRESTO's online data collection approach [22]. The video-chat method allowed for faceto-face contact with participants and reading of nonverbal and contextual data. Three participants ( 2 female non-inviters and 1 male non-respondent) opted for an audio-only interview.

A female $\mathrm{PhD}$ student trained in qualitative methods (A.H.) conducted in-depth interviews and moderated the online focus group. Interviews followed a semi-structured interview guide tailored to a participant's specific respondent group. A researcher experienced in qualitative research methods (S.R) reviewed the interview guide for content, format and interpretability. Questions included participants' experience, behaviors, opinions/values, and feelings about choosing to participate, choosing not to participate, or choosing not to invite one's male partner. Interviews also asked participants their opinions of male participation in fertility research in general, and about specific barriers or facilitators to their participation. Preliminary analysis of the in-depth interviews informed the focus group interview guide. The interview guide followed a similar format as the in-depth interviews; however, the moderator additionally relayed findings from the in-depth interviews to triangulate preliminary thematic findings [25]. We digitally recorded interviews through Zoom software. Each participant received a $\$ 100$ gift card.

\section{Ethical approval}

The Boston University Medical Campus institutional review board approved this research.

\section{Analysis}

We uploaded professional transcripts of the interviews to NVIVO Version 12. Three study staff members (1 Ph.D. level and 2 masters level coders) conducted an inductive content analysis of the interviews [26]. We analyzed all interviews of the same respondent type separately, beginning with male respondents. To understand the data as a whole, coders first read through all transcripts of the respondent type. Coders then began coding one information-rich interview by reading through the interview and summarizing important phrases, sections, or quotations. Using emergent patterns, coders rearranged the summarized sections through an iterative process based on how they relate to each other [27]. Coders labeled each arrangement to create a set of codes. The coders met throughout this process to discuss and review the proposed set of codes, and address inconsistencies or disagreements using a consensus approach [28]. Using an agreed-upon codebook, each coder then separately coded the remaining interviews and met periodically throughout the process to review and update codes and reach consensus on any discrepancies. We repeated this process for male non-respondent interviews, female non-inviter interviews, and the focus group. Coders used the same codebook for each respondent type, however the codebook evolved throughout the coding process. Throughout the coding process, coders reviewed the video of each interview to better immerse themselves in the data, and identify non-verbal cues. We analyzed the final coded interviews for patterns within and across respondent types to identify emergent factors important to male participation in fertility research.

\section{Results}

Table 2 presents descriptive statistics of the purposeful sampling criteria. In each respondent type, there was variation in education, geography, pregnancy attempt times, female age, and relationship length. However, $85.7 \%$ of the one-on-one interview participants and $80 \%$ of the focus group participants were non-Hispanic white. The average length of the in-depth interviews was $37 \mathrm{~min}$, and the focus group lasted $1 \mathrm{~h}$ and $23 \mathrm{~min}$.

Five factors emerged from the data important to male participation in PRESTO and/or fertility research in general (Table 3), including: (1) seeking knowledge but fearing results; (2) recognizing the importance of fertility issues; (3) believing fertility and pregnancy are women's issues; (4) avoiding difficult conversations; and (5) supporting their partner.

\section{Seeking knowledge but fearing results}

Male respondents participated to gain an understanding of their own reproductive health, particularly knowledge of semen quality or dietary behaviors. Males invited by PRESTO investigators to provide semen samples commented on how getting concrete results back about their reproductive health was a strong motivation for participation, and an opportunity for empowerment.

\section{"And just like, knowledge is power. I was looking for- ward to getting a little bit more knowledge about my own body."}

For male respondents who struggled to conceive in the past, gaining knowledge about their reproductive health was an important benefit of the study. Research 
Table 2 Demographic characteristics of participants by respondent type ${ }^{a}$

\begin{tabular}{|c|c|c|c|c|}
\hline & \multicolumn{3}{|c|}{ One-on-one interviews } & \multirow{2}{*}{$\begin{array}{l}\text { Focus group participants } \\
\text { Male respondents }(n=10)\end{array}$} \\
\hline & $\begin{array}{l}\text { Male respondents } \\
(n=6)\end{array}$ & $\begin{array}{l}\text { Male non-respondents } \\
(n=4)\end{array}$ & $\begin{array}{l}\text { Female non-inviters } \\
(n=4)\end{array}$ & \\
\hline & n (\%) & n (\%) & n (\%) & n (\%) \\
\hline \multicolumn{5}{|l|}{ Race/ethnicity } \\
\hline Non-hispanic white & $6(100)$ & $2(50)$ & $4(100)$ & $8(80)$ \\
\hline Non-hispanic Black & $0(0)$ & $0(0)$ & $0(0)$ & $0(0)$ \\
\hline Non-hispanic other race & $0(0)$ & $2(50)$ & $0(0)$ & $0(0)$ \\
\hline Hispanic/Latina & $0(0)$ & $0(0)$ & $0(0)$ & $2(20)$ \\
\hline \multicolumn{5}{|l|}{ Education } \\
\hline$<$ College & $1(17)$ & $1(25)$ & $3(75)$ & $2(20)$ \\
\hline$\geq$ College & $5(83)$ & $3(75)$ & $1(25)$ & $8(20)$ \\
\hline \multicolumn{5}{|l|}{ Geography } \\
\hline US Northeast & $2(33)$ & $1(25)$ & $0(0)$ & $2(20)$ \\
\hline US South & $1(17)$ & $1(25)$ & $2(50)$ & $3(30)$ \\
\hline US Midwest & $2(33)$ & $1(25)$ & $2(50)$ & $1(10)$ \\
\hline USWest & $1(17)$ & $1(25)$ & $0(0)$ & $2(20)$ \\
\hline Canada & $0(0)$ & $0(0)$ & $0(0)$ & $2(20)$ \\
\hline \multicolumn{5}{|c|}{ Pregnancy attempt time at enrollment ${ }^{b}$} \\
\hline$<3$ cycles & $5(83)$ & $3(75)$ & $3(75)$ & $7(70)$ \\
\hline$\geq 3$ cycles & $1(17)$ & $1(25)$ & $1(25)$ & $3(30)$ \\
\hline \multicolumn{5}{|l|}{ Relationship length ${ }^{c}$} \\
\hline$<5$ years & $1(17)$ & $1(25)$ & $2(50)$ & $2(20)$ \\
\hline$\geq 5$ years & $5(83)$ & $3(75)$ & $2(50)$ & $8(80)$ \\
\hline \multicolumn{5}{|l|}{ Female age $^{d}$} \\
\hline$<30$ years & $1(17)$ & $2(50)$ & $4(100)$ & $8(80)$ \\
\hline$\geq 30$ years & $5(17)$ & $2(50)$ & $0(0)$ & $2(20)$ \\
\hline \multicolumn{5}{|l|}{ Male age ${ }^{e}$} \\
\hline$<30$ years & $1(17)$ & $1(25)$ & $4(100)$ & $3(30)$ \\
\hline$\geq 30$ years & $5(17)$ & $3(75)$ & $0(0)$ & $7(70)$ \\
\hline
\end{tabular}

a Male respondents are men who participated in Pregnancy Study Online (PRESTO); male non-respondents are men who were invited to PRESTO but declined to participate; female non-inviters are women who were in enrolled in PRESTO but declined to invite their male partners to participate

b Pregnancy attempt time at enrollment in PRESTO. Reported by female partners.

c Refers to relationship length at time of enrollment or invitation to PRESTO

d For male participants, refers to age of female partner at the time of enrollment or invitation to PRESTO

e For female participants, refers to age of male partner at the time of enrollment in PRESTO

participation was one extra thing they could do to help their fertility.

"...the value about sperm count and motility I think is really interesting because so, we've - we have had some issues getting a pregnancy to stick. And like, that's another piece of data that's valuable in helping that. And so, we're still working through our fertility situation. And the opportunity to have maybe a little bit of data or understanding of what's going on through this, it's another opportunity."

While knowledge motivated participation, it was a barrier as well. Male respondents and focus group participants feared receiving information that their semen is of poor quality. Participants felt that some men might prefer to have no information on their reproductive health rather than bad information.

"People are more happy to know that they are virile men and they don't want to have like questioning of what they have wrong with them. And so,- that's my assumption, that people would rather not know or go under the idea that they have nothing wrong versus going through this process."

Men who participated in the semen testing activities of PRESTO confirmed their nervousness around getting 


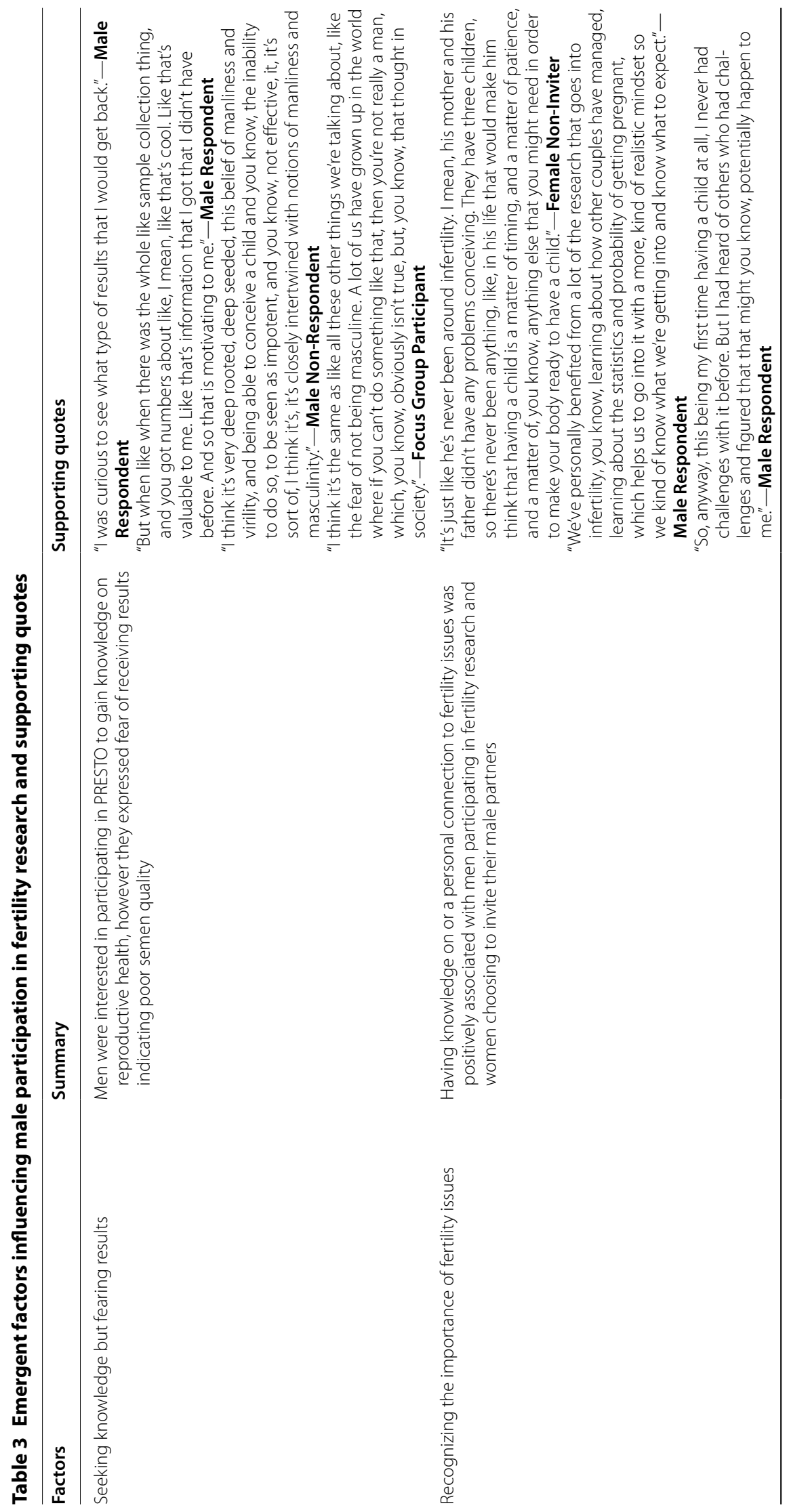




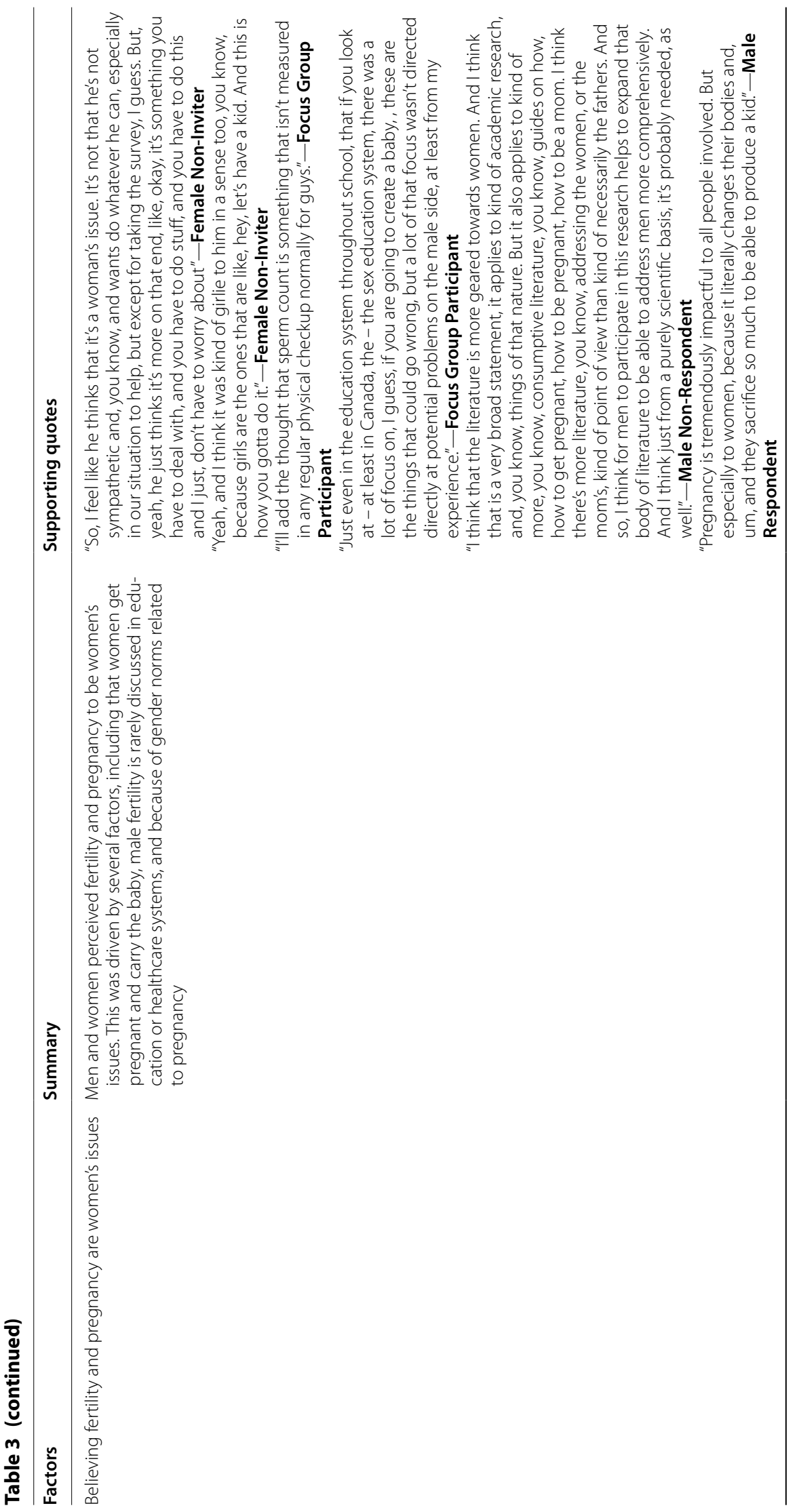




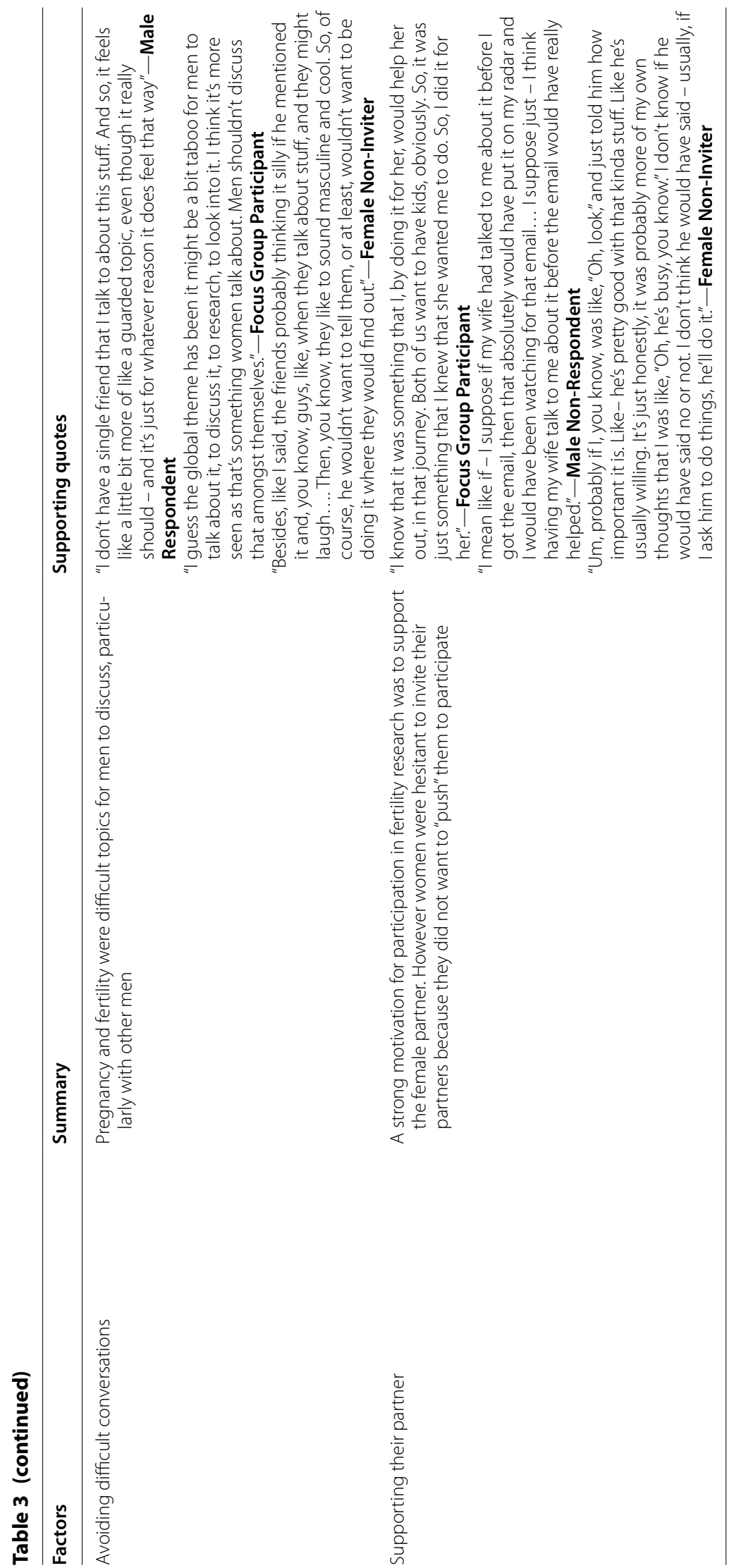


results back, and subsequent relief upon getting a good result.

"I did the semen sample already. I'm one of the lucky ones. Everything came back in the optimal range and - I've got to tell you, I high-fived my wife. I was like so excited. I was like, "Yeah, yeah, I got it," because it was definitely a level of concern that existed in our minds."

Interviewees connected these fears of obtaining bad results to feelings of vulnerability, and to the idea that virility is intertwined with the cultural concept of masculinity. Both respondents and non-respondents discussed how receiving a result that indicates a fertility problem might compromise their own feelings of masculinity.

"You get a result that's not outstanding and you can feel like less of a man."

\section{Recognizing the importance of fertility issues}

Recognition that fertility, and the process of conceiving, is an important and potentially emotionally taxing health issue was a factor in male participation or lack of participation in PRESTO, and for women in their decision to invite their partners. Many women felt their male partners had little knowledge about fertility or preconception. Some perceived that their partners believed that pregnancy is always simple, quick, and easy rather than a sometimes complex, lengthy, and stressful process. These women felt their partner's beliefs stemmed from little exposure to experiences of infertility, either personally or in their families.

"I just think he doesn't understand, you know. Like he thinks it's easy. It's like one and done. And yeah, okay, it takes a few months"

These feelings contributed to some women's decisions not to invite their partners to participate. Because they perceived their partners lacked knowledge, some women believed their partners would not invest in the research process.

"I don't think he would've been invested in it because

he really had no reason to think that there would ever be a problem in conceiving a child."

One male non-respondent discussed how he personally had never been exposed to experiences of infertility. He expressed doubt that lifestyle factors play a role in conception because he had impregnated his partner while using marijuana and other drugs. His own experience with successful conception led him to believe that fertility research offered little benefit to him or society.
"I didn't live a healthy lifestyle. I mean, I did exercise and stuff here and there, but I mean, I smoked. I smoked pot all the time. I mean, I grew up smoking pot. And another thing is, at the time she got pregnant, I was on narcotics for my neck as well. Now they say if you - take this, that, it'll lessen your chances and all that. It's not true, you know."

In contrast, personal experiences with pregnancy loss positively influenced participation. Some mentioned personally benefitting from fertility and pregnancy research, which encouraged their own participation in PRESTO. One non-respondent male who expressed regret about not participating in PRESTO revealed that a prior miscarriage increased his desire for more information on his personal reproductive health, but also the desire to help others going through similar scenarios.

"Oh, yeah, so, we had a miscarriage last year, and so, because of that, I think I would have been much more likely to want to participate, understanding that, you know, because of that negative experience, we sort of wanted to get more information, and so we'd understand the value of helping to provide that information to researchers. So, you know, again, another answer that kind of suggests that I would have done the opposite of what I did."

Others mentioned that having friends who experienced fertility issues helped them realize that they might have their own difficulties conceiving. Participants felt this knowledge increased their desire to participate in order to help others.

"I'm sure we all have friends who have tried unsuccessfully to have kids, and so just the idea that maybe if I can be one more data point that would help a study, you know, who knows, then maybe [it will] help more people who want to become pregnant - then I want to help out with that.

\section{Believing fertility and pregnancy are women's issues}

Both women and men perceived that fertility and pregnancy are women's health issues. Participants from each respondent type framed women as caring more about fertility and pregnancy than men.

"If I had to say one thing though, it's just that I suppose I feel like males in general are just not as interested in fertility stuff, as you guys are probably finding out."

Participants discussed how society often views subfertility or infertility as health issues that only affect women, and that researchers could improve recruitment of men 
in fertility studies by communicating that men can also contribute to couple subfertility or infertility.

"I think there's a perception - I think many people would agree with this -that infertility is a woman's problem... I think in terms of getting more men to participate, if you can quantify when it is the male problem, if you can make a stronger case there and then the wife or the partner can then use that as a way to persuade hopefully their husband or spouse."

Cultural factors influenced beliefs that fertility and pregnancy are women's issues. Several participants referenced fertility and pregnancy as feminine topics. These participants discussed traditional gender roles or cultural expectations for women to want children. One female participant mentioned how women are often the person in a relationship to initiate the process of trying to conceive. A male non-respondent mentioned how he viewed fertility and pregnancy as a "girl topic" because he rarely discussed pregnancy with his peers growing up, but perceived that women have these conversations often.

"I haven't had a lot of conversations growing up about like, "Oh how many kids do you want to have?" And, "What do you want to name your children?" And I never had conversations like that with my friends. So, I guess that's just not a topic that for some reason I never went to with friends or anything growing up. But it was something that I, you know, would hear girls that I knew talking about a lot. And they would be interested in it, so I guess it just in my mind got associated with that's a girl topic."

Some participants mentioned that male fertility is rarely discussed within educational and healthcare systems. Participants felt that men have to actively seek out information on fertility if they are interested in learning more. In contrast, they believed that the medical profession regularly discusses the topics of fertility and pregnancy with women.

"And also, just like women have doctors' appointments and stuff where they talk about fertility and things. I feel like men are often missing out on that and they don't really have a chance unless they seek it out to discuss fertility."

In general, both respondents and non-respondents felt that most pregnancy-related literature, including books, online forums, and academic research focuses on the female perspective.

"If you go to a forum or something that deals with trying to conceive or pregnancies, the balance, the gender balance is skewed heavily towards women, as opposed to men."

One non-respondent mentioned that expanding this consumptive literature might be one benefit of men participating in fertility research.

"I think for men to participate in this research helps to expand that body of literature to be able to address men more comprehensively."

Both men and women mentioned that the perception of fertility and pregnancy being women's issues also likely stems from the fact that biologically, women get pregnant and carry the child. The drastic changes to the female's body would naturally lead women to greater interest and investment in the topic.

"I suppose one of the reasons could be, during a pregnancy, there's no changes to a man's body, but the woman's body goes through a lot. I suppose if there was a situation where there was going to be drastic changes to my body, I want to know about it too."

One non-respondent did not want overstep his boundaries, or take ownership of a process that primarily concerned female bodies.

"One barrier that I feel a lot as a guy, me personally, and I think a lot of other guys, especially my age, feel, when it comes to this kinda thing, I think I kind of alluded to this a little bit, but like, not wanting to overstep my bounds, you know, like, not wanting to say to my wife, "Look, I've been doing a lot of research, and you know, this is what I think you need to start doing with your body," I think that - I feel that's really out of place, you know?".

Despite a perception of fertility and pregnancy as women's issues, participants also felt that men should participate in fertility and pregnancy research to include the male perspective in this predominately female-dominated space.

"I think that it's important for men to have their point of view represented."

\section{Avoiding difficult conversations}

All participants felt that men struggled to talk about fertility and pregnancy, particularly among friends or peers.

"I would never talk about this study to other guys that I know."

Most men perceived that women have an easier time talking about their experiences with pregnancy or trying to conceive.

"I think it's a lot easier for women to talk about 
it... than it is for a guy because I can't walk up to my buddy be like, "Hey, man, you know, my sperm count's low." It's just not kind of the conversation that you'd have. But, the conversations between my wife and her friends, I know always seem to lead to how much she wants to be a mom."

Participants felt that friends or peers might ridicule men for discussing pregnancy or fertility. One female participant discussed how her husband's friends would think discussing fertility and pregnancy was a "silly" conversation, and that they would laugh at her husband if he brought it up.

"...friends probably think it's silly if he mentioned it and, you know, guys, like, when they talk about stuff, and they might laugh..."

One focus group participant had openly discussed his participation in the study with his co-workers, and the participant perceived that it was an uncomfortable and "off-putting" topic.

"I know for myself, working in the marine industry, where you do deal with that A-type masculine personality a lot, I'm an anomaly within my company. I openly talked about that I was in the [study]. But definitely, you could tell it was like an off-puttinglike, it was a weird thing to talk about."

Participants relayed that one reason men feel uncomfortable talking about pregnancy and fertility is that it is a sensitive topic alluding to sex.

"I was just gonna say that we can use these words of trying and conceiving, but when it comes down to it, I mean, you're talking about sex and that just generally is not just something guys talk about in any sort of detail with each other."

One male non-respondent attributed his own discomfort to rarely discussing sex or reproduction with his own family growing up.

"I think it's a cultural thing mostly. Um, I know my family, we grew up, you know, when I was a kid, we didn't talk about things like sex or reproduction or, you know, women - women's health issues, stuff like that, it was just kind of impolite, and really, it was like considered impolite. You know, that's rude. You don't talk about that stuff. I think a lot of that is still carried over into the modern age. I think that slowly the attitudes are changing, but, you know, I know a lot of people my age that are really uncomfortable talking about sex because that's the environment they grew up in."
Another focus group participant's reservations around talking about pregnancy with peers were because it involved his wife's body-a subject that he felt was hers to control rather than his.

"Even if she's not there, if it's a group that involves her, if I'm talking about fertility and, uh, getting pregnant, her getting pregnant, I'm talking about her getting pregnant, not me. So I definitely don't want to talk about it to try and give it - it's her subject to control who knows about it."

\section{Supporting their partner}

Nearly all male respondents cited their partner as the sole or primary reason for participation in PRESTO. Participating was a way to support their partner.

\section{"What motivated me was: Number one, I mostly did it to support my wife."}

Beyond just agreeing to participate, partners often influenced participants to complete the study. Some participants completed the study activities so that that the data on them as a couple was as comprehensive as possible. Others felt the study would be more appealing to men if researchers invited couples to participate together. Completing the study together could create a teamwork mentality to motivate both participants to finish providing data.

"If you're on a team with your spouse, you not only make a commitment to the study, but to your spouse as well. Obviously, you'll have more initiative to complete the questionnaires and participate in the focus groups."

Even among non-respondents, several emphasized that if their partners had reminded them about the study or encouraged them to participate, they likely would have participated.

"Yeah, I mean, listen, if she told me to do it, I would just do it. If I saw that she was excited about it, then I would be much more inclined to do it, as well. So I think it's as simple as that."

Similarly, women concurred that if they had invited their partners and talked to them about participating, then their partners would participate to support them.

"I think if I would have talked to him about it as well as send the email, then probably. I mean, if I had just sent the email, he'd be like what is this? But if I talked to him at home, too... because I'm doing it and I'm interested and I'm excited or something, more like, he'd do it for me, you know." 
However, women also did not want to feel as if they were pushing their partners to participate.

"...but it was just one of those things that I didn't wanna be pushing something on him that he didn't necessarily feel was needed at this point."

\section{Discussion}

This qualitative study on male participation in fertility research reveals several important factors contributing to male participation in a large preconception cohort study. All three respondent types-men who participated, men who chose not to participate, and women who chose not to invite their male partners to participate-held some common perspectives. Most participants perceived that fertility is a women's health issue and is a difficult topic for men to discuss, and men expressed fears of infertility tied to masculinity. However, men participated in fertility research to support their partners, to provide data that could help others, and to learn more about their own reproductive health.

Both male and female participants felt that males were not connected to fertility and pregnancy in general, and that these were women's health issues. They attributed this disconnect to a range of factors, including biology, societal barriers, and cultural norms. In prior research, men from the general United Kingdom population felt that women play a more important role in reproductive health decisions because they get pregnant and carry the child, and that society rarely encourages men to engage in discussions of fertility and pregnancy [15]. Our work demonstrates this belief also influences male engagement in fertility research among North American men and women actively trying to get pregnant. However, while men perceived fertility and pregnancy to be women's issues, they also expressed a desire for more research and literature on male fertility, and felt that participating in PRESTO was an opportunity for the male voice to be heard. Researchers developing recruitment materials for male fertility studies may wish to emphasize that participation is an opportunity to provide the male perspective to fertility research.

Men desired to learn more about their own reproductive health but were apprehensive about results that might indicate fertility issues. Some men felt that fertility issues would make them feel less masculine, and that a fear of poor semen quality made them reluctant to participate in the semen testing substudy. These findings align with prior studies showing a perceived tie between virility and feelings of masculinity [29-31], and an association between diagnosis and treatment of infertility and poor mental health among men [32]. Tailoring counseling to men's fertility results can help improve psychological adaptation to fertility issues [33, 34]. Therefore, one solution for researchers aiming to recruit men into fertility studies may be to offer resources on how to interpret any feedback they do receive, or resources for coping with difficulties conceiving.

Personal connections or past exposure to fertility issues positively contributed to men's decision to participate or women's decision to invite their male partners. Lack of knowledge on potential difficulties in the conception process may inhibit male participation in fertility research. A prior systematic review similarly found men tend to overestimate chances of spontaneous conception [35]. Many men in our study also expressed a general discomfort in discussing fertility issues, as reported in prior research [15]. Participants rarely talked about fertility or pregnancy with their peers, and felt that it was a sensitive topic because it alludes to sexual activity, or involves their partner's body. These data highlight the importance of communicating research on fertility to the general public. Fertility researchers could work with health communication professionals to communicate study results to the public, or help to develop educational curriculums. If society normalizes talking about male fertility and male involvement in pregnancy, this may help men feel more comfortable discussing fertility and pregnancy with each other and with researchers.

Most men discussed participating as a way to support their female partners. Even men who had chosen not to participate conceded that they would have participated if their partners had encouraged them. The women's perspective clearly demonstrated this as well; women reported that if they asked their partners to participate and conveyed that it was personally important to them, they were sure their partners would have participated. However, some women chose not to invite their partners partly because they did not want to feel like they were pushing them to do something against their will. This perception that participation in fertility research is a favor to the female partner likely decreases the likelihood of inviting male partners. These results indicate a potential tradeoff for researchers aiming to recruit male participants by using the female partners as gatekeepers. While the influence from the female partner likely facilitates male engagement, it simultaneously acts as a barrier for women to invite their partners to participate in the first place.

There are several limitations to this study. We attempted to recruit participants diverse in several socio-demographic factors. While we achieved diversity in education, geography, and pregnancy attempt times, $85.7 \%$ of the participants in the one-on-one interviews and $80 \%$ of the participants in the focus group were non-Hispanic White. In addition, we 
purposefully targeted certain men as information-rich cases that could provide insight on full research participation, but they were likely more engaged in fertility research than the average male participant. There were also low response rates among eligible participants. However, focus group participants confirmed the results derived from respondent and non-respondent interviews, which lends confidence to the trustworthiness of the data [25]. Finally, the interviewer for this study was a female Ph.D. student. A male interviewer might have made participants more comfortable to discuss the sensitive nature of male fertility and male participation in fertility research. In addition, there is the possibility of social desirability bias (i.e., participants providing responses they perceive to be socially acceptable). However, the experience that that female interviewer has in qualitative methods may have mitigated this. Finally, results may not be transferrable to other populations with different cultural norms and attitudes about sex or fertility.

\section{Conclusions}

The recruitment of men into fertility studies will improve our understanding of male factors contributing to fertility and reproductive health issues. In this qualitative study, we reveal several factors affecting whether men participate in fertility research, as well as factors influencing a woman's decision to invite her male partner to participate. Results suggest that more education and health communication on male fertility and reproductive health could help increase male participation in reproductive health research.

\section{Acknowledgements}

The authors would like to thank the men and women who participated in these in-depth interviews and the focus group.

\section{Authors' contributions \\ AFH led in the design of the study, conducted the interviews and moderated the focus group, conducted data analysis, and wrote the first draft of the manuscript. AZ and JN helped in design and moderation of the focus group, conducted data analysis, and edited the manuscript. EEH and SR provided consultation in the design of the study, helped interpret study findings, and edited the manuscript. LAW designed the parent study, contributed to the substudy design, supervised data collection, helped interpret study findings, and edited the manuscript. All authors read and approved the final manuscript.}

\section{Funding}

This work was supported by the Eunice Kennedy Shriver National Institute for Child Health and Human Development (R01-HD086742).

\section{Availability of data and materials}

Data sharing is not applicable to this article as no datasets were generated or analysed during the current study.

\section{Ethical approval and consent to participate}

The Boston University Medical Campus institutional review board approved this research.
Consent for publication

Not applicable.

\section{Competing interests}

The authors have no competing interests to report.

\section{Author details}

${ }^{1}$ Department of Epidemiology, Boston University School of Public Health, 715 Albany Street, Boston, MA 02188, USA. ${ }^{2}$ Department of Information Systems, Boston College Carroll School of Management, Chestnut Hill, MA 02467, USA.

Received: 13 August 2020 Accepted: 12 November 2020

Published online: 23 November 2020

\section{References}

1. Irvine DS. Epidemiology and aetiology of male infertility. Hum Reprod. 1998;13(Supplement 1):33-44.

2. NICHD Infertility and Fertility Research Goals. 2017. (Cited 2020 Apr 24). https://www.nichd.nih.gov/health/topics/infertility/researchinfo/goals.

3. Wesselink AK, Rothman KJ, Hatch EE, Mikkelsen EM, Sørensen HT, Wise LA. Age and fecundability in a North American preconception cohort study. Am J Obstet Gynecol. 2017;217(6):667.e1-667.e8.

4. Eisenberg ML, Meldrum D. Effects of age on fertility and sexual function. Fertil Steril. 2017;107(2):301-4

5. Sharma R, Harlev A, Agarwal A, Esteves SC. Cigarette smoking and semen quality: a new meta-analysis examining the effect of the 2010 World Health Organization Laboratory methods for the examination of human semen. Eur Urol. 2016;70(4):635-45.

6. Sapra KJ, Barr DB, Maisog JM, Sundaram R, Buck Louis GM. Time-to-Pregnancy Associated With Couples' Use of Tobacco Products. Nicotine Tob Res. 2016;18(11):2154-61.

7. Wesselink AK, Hatch EE, Rothman KJ, Mikkelsen EM, Aschengrau A, Wise LA. Prospective study of cigarette smoking and fecundability. Hum Reprod. 2019;34(3):558-67.

8. Eisenberg ML, Kim S, Chen Z, Sundaram R, Schisterman EF, Buck Louis GM. The relationship between male BMI and waist circumference on semen quality: data from the LIFE study. Hum Reprod. 2014;29(2):193-200.

9. Sundaram R, Mumford SL, Louis GMB. Couples'body composition and time-to-pregnancy. Hum Reprod. 2017;32(3):662-8.

10. Wise LA, Rothman KJ, Mikkelsen EM, Sørensen HT, Riis A, Hatch EE. An internet-based prospective study of body size and time-to-pregnancy. Hum Reprod. 2010;25(1):253-64.

11. Schmidt L, Sobotka T, Bentzen JG, Nyboe AA. Demographic and medical consequences of the postponement of parenthood. Hum Reprod Update. 2012;18(1):29-43.

12. Sharma R, Biedenharn KR, Fedor JM, Agarwal A. Lifestyle factors and reproductive health: taking control of your fertility. Reprod Biol Endocrinol. 2013;11(1):66.

13. Homan GF, Davies M, Norman R. The impact of lifestyle factors on reproductive performance in the general population and those undergoing infertility treatment: a review. Hum Reprod Update. 2007;13(3):209-23.

14. Stykes JB. Methodological considerations in couples' fertility intentions: missing men and the viability of Women's Proxy Reports. Matern Child Health J. 2018;22(8):1164-71.

15. Grace B, Shawe J, Johnson S, Stephenson J. You did not turn up... I did not realise I was invited...: understanding male attitudes towards engagement in fertility and reproductive health discussions. Hum Reprod Open. 2019;3:1-7.

16. Law C. Men on the margins? Reflections on recruiting and engaging men in reproduction research. Methodol Innov. 2019. https://doi. org/10.1177/2059799119829425.

17. Men HF, Adopt A. J Fam Issues. 2013;34(8):1059-80.

18. Hanna E, Gough B. Men's accounts of infertility within their intimate partner relationships: an analysis of online forum discussions. J Reprod Infant Psychol. 2017;35(2):150-8.

19. Greene ME, Biddlecom AE. Absent and problematic men: demographic accounts of male reproductive roles. Popul Dev Rev. 2000;26(1):81-115. 
20. Culley L, Hudson N, Lohan M. Where are all the men? the marginalization of men in social scientific research on infertility. Reprod Biomed Online. 2013;27(3):225-35.

21. Almeling R, Waggoner MR. More and less than equal: how men factor in the reproductive equation. Gend Soc. 2013;27(6):821-42.

22. Wise LA, Rothman KJ, Mikkelsen EM, Stanford JB, Wesselink AK, Mckinnon $C$, et al. Design and conduct of an internet-based preconception cohort study in North America: pregnancy study online. Paediatr Perinat Epidemiol. 2015;29(4):360-71.

23. Lambert SD, Loiselle CG. Combining individual interviews and focus groups to enhance data richness. J Adv Nurs. 2008;62(2):228-37.

24. Ritchie J, Lewis J, Elam RG. Selecting samples. In: Qualitative research practice: a guide for social science students and researchers. Thousand Oaks: SAGE; 2013. p. 111-45.

25. Patton MQ. Qualitative evaluation and research methods. 2nd ed. Thousand Oaks: Sage Publications; 1990.

26. Hsieh H-F, Shannon SE. Three approaches to qualitative content analysis Qual Health Res. 2005;15(9):1277-88

27. Corbin J, Strauss A. Grounded theory research: procedures, canons, and evaluative criteria. Qual Sociol. 1990;13(1):3-21.

28. Bradley EH, Curry LA, Devers KJ. Qualitative data analysis for health services research: developing taxonomy, themes, and theory. Health Serv Res. 2007;42(4):1758-72.

29. Dudgeon MR, Inhorn MC. Gender, masculinity, and reproduction: anthropological perspectives. Int J Mens Health. 2003;2(1):31-56.
30. Sylvest R, Fürbringer JK, Pinborg A, Koert E, Bogstad J, Loessl K, et al. Low semen quality and experiences of masculinity and family building. Acta Obstet Gynecol Scand. 2018;97(6):727-33.

31. Barns LW. Conceiving masculinity: male infertility, medicine, and identity. Temple University Press, editor. Philadelphia, PA: Temple University; 2014.

32. Fisher JRW, Hammarberg K. Psychological and social aspects of infertility in men: an overview of the evidence and implications for psychologically informed clinical care and future research. Asian J Androl. 2012;14(1):121-9.

33. Sylvest R, Koert E, Vittrup I, Birch Petersen K, Hvidman HW, Hald F, et al. Men's expectations and experiences of fertility awareness assessment and counselling. Acta Obstet Gynecol Scand. 2018;97(12):1471-7.

34. Martins MV, Basto-Pereira M, Pedro J, Peterson B, Almeida V, Emília CM. Male psychological adaptation to unsuccessful medically assisted reproduction treatments: a systematic review. Hum Reprod Update. 2016;22(4):466-78

35. Hammarberg K, Collins V, Holden C, Young K, McLachlan R. Men's knowledge, attitudes and behaviours relating to fertility. Hum Reprod Update. 2017;23(4):458-80.

\section{Publisher's Note}

Springer Nature remains neutral with regard to jurisdictional claims in published maps and institutional affiliations.
Ready to submit your research? Choose BMC and benefit from:

- fast, convenient online submission

- thorough peer review by experienced researchers in your field

- rapid publication on acceptance

- support for research data, including large and complex data types

- gold Open Access which fosters wider collaboration and increased citations

- maximum visibility for your research: over 100M website views per year

At BMC, research is always in progress.

Learn more biomedcentral.com/submissions 